\title{
Processos de formação do sambaqui Jabuticabeira-II: interpretações através da análise estratigráfica de vestígios vegetais carbonizados
}

\author{
Gina Faraco Bianchini* \\ $\mathrm{MaDu}$ Gaspar* \\ Paulo DeBlasis * * \\ Rita Scheel-Ybert*
}

\begin{abstract}
BIANCHINI, G.F.; GASPAR, M.D.; DEBLASIS, P.; SCHEEL-YBERT, R. Processos de formação do sambaqui Jabuticabeira-II: interpretações através da análise estratigráfica de vestigios vegetais carbonizados. R. Museu Arq. Etn., São Paulo, n. 21, p. 51-69, 2011.
\end{abstract}

Resumo: Este trabalho apresenta a análise antracológica de uma área funerária do sítio Jabuticabeira-II, a qual é comparada aos resultados da análise da camada de cobertura do mesmo perfil realizada por Scheel-Ybert (2001). Todo o sedimento foi coletado de acordo com as feições arqueológicas. A identificação dos fragmentos foi feita em microscópio de luz refletida a partir da estrutura anatômica da madeira. Foram evidenciadas diferenças significativas entre a camada de cobertura e a área funerária e apresentados dados que sugerem a ocorrência de seleção de alguns elementos relacionados ao ritual funerário.

Palavras-chave: Ritual funerário - Carvões - Antracologia - Sambaqui.

\section{Introdução}

$\mathrm{N}$ a Arqueologia Brasileira, o estudo de restos vegetais tem se revestido de uma importância cada vez maior, contribuindo para desvendar uma série de questões relacionadas às culturas do passado. No entanto, até meados da década de 1990, sua presença era apenas ocasionalmente registrada, de modo geral restrita a poucos elementos mais conspícuos, mas rara-

(*) Museu Nacional, Universidade Federal do Rio de Janeiro. Departamento de Antropologia. <ginabianchini@ufrj.br>; <madugaspar@terra.com.br>; <scheelybert@mn.ufrj.br> ${ }^{(* *)}$ Museu de Arqueologia e Etnologia da Universidade de São Paulo.<deblasis@usp.br> mente valorizada, e menos ainda interpretada em termos de cultura material.

O termo cultura material se refere a uma ampla série de objetos produzidos ou modificados pelo homem. Incluem-se aí tipos especiais de objetos tais como ossos, argila, rochas, madeiras, conchas... Quando depositados inteiros ou fragmentados de maneira particular, suas texturas, cores, formas, e suas relações deposicionais em diferentes contextos (assentamentos, habitações, rituais, sepultamentos etc) podem ser analisadas de forma produtiva nos termos em que objetificam tipos particulares de relações sociais e de concepções de mundo (Tilley 2004, 2006).

Os fragmentos de carvões depositados no contexto arqueológico incluem-se nesta catego- 
Processos de formação do sambaqui Jabuticabeira-II: interpretações através da análise estratigráfica de vestígios vegetais carbonizados. R. Museu Arq. Etn., São Paulo, n. 21, p. 51-69, 2011.

ria de objetos especiais, na medida em que: são produtos da modificação humana de objetos naturais (no caso as árvores); suas relações deposicionais podem apresentar padrões que se distinguem segundo os diferentes contextos; e todos os processos sujeito/objeto, mesmo aqueles que antecedem a deposição (seleção, coleta, transporte), incorporam uma série de idéias, movimentos, ações, mitos, restrições, conhecimentos etc. O presente estudo se alinha a estas premissas e tem por objetivo demonstrar que a análise e interpretação dos restos de carvão podem fornecer informações que vão além da reconstituição paleoambiental.

Questões relacionadas à dieta e subsistência sempre estiveram no rol dos principais interesses das pesquisas em sambaquis. Porém, durante muito tempo, os construtores de sambaquis foram considerados como pertencendo a sociedades bastante simples, com uma economia baseada essencialmente na coleta de moluscos, complementada pela caça e pela pesca. Esta premissa, associada à escassez de vestígios vegetais que em geral caracteriza o registro arqueológico deste tipo de sítio, contribuiu para mascarar a importância dos vegetais.

Mais tarde, o desenvolvimento de estudos zooarqueológicos e de isótopos estáveis demonstrou a importância da pesca no sistema de subsistência dos sambaquieiros desde os primórdios da ocupação das zonas costeiras (Bandeira 1992; Figuti 1993; De Masi 2001; Klökler 2001). Considera-se atualmente que os moluscos tenham sido um elemento secundário na dieta, mas que tiveram grande importância como material de construção (Afonso e DeBlasis 1994; Klökler 2001; Gaspar 2003).

Atualmente as pesquisas arqueológicas sugerem que os sambaquis, construções monumentais, foram feitos com a intenção de serem marcos paisagísticos (DeBlasis et al. 1998, 2007), os quais eram locais de habitação e de sepultamento, seja concomitantemente, como é postulado para os sítios do Sudeste (Gaspar 1998; Barbosa 2001), ou não, como foi sugerido para o Sul do Brasil, onde parece ter havido uma especialização de pelo menos alguns sítios como locais estritamente funerários (Fish et al. 2000). Os assentamentos eram implantados estrategi- camente para aproveitar áreas de intersecção ecológica, ricas em pescado, moluscos e recursos vegetais (Gaspar 1991, 1998, 2000; Scheel-Ybert et al. 2003). Sua organização espacial, formando agrupamentos de sítios, sugere estabilidade territorial (Gaspar 1998) e a ocupação contínua dos sítios por um grande período de tempo indica sedentarismo (Gaspar 1996).

Só mais recentemente é que análises antracológicas vieram contribuir para demonstrar a importância dos vegetais para os sambaquieiros e sua relação com o meio vegetal. Associados a estudos bioantropológicos, de patologia dental, e a análises de implementos líticos, estes dados vêm subsidiando a hipótese de que um cultivo incipiente, provavelmente horticultura, poderia ter sido praticado por estas populações. Propõe-se que, ainda que baseada em recursos marinhos, sua dieta tenha sido ampla, incorporando uma grande variedade de plantas selvagens e possivelmente algumas cultivadas, incluindo algumas espécies tuberosas com potencial cariogênico (Scheel-Ybert et al. 2003).

O sítio Jabuticabeira-II é um dos sambaquis de grande porte do litoral de Santa Catarina. Ocupa uma área de aproximadamente 8,4 ha, elevando-se a cerca de $10 \mathrm{~m}$ de altura e perfazendo $400 \mathrm{~m}$ no seu eixo maior e $250 \mathrm{~m}$ na diagonal (Simões 2007). Embora parcialmente destruído há algumas décadas por atividades de mineração, atualmente ele é um dos sambaquis mais extensivamente estudados na história da arqueologia brasileira. Os resultados sugerem que este sambaqui foi construído em torno do programa funerário (Klökler 2001).

Os conjuntos "área funerária/camadas de cobertura", descritos mais à frente, se superpõem sucessivamente ao longo do sítio, indicando que os processos de formação estariam associados à repetição de rituais funerários, provavelmente relacionados a festins fúnebres (Fish et al. 2000; Klokler 2001, 2008).

Embora uma análise antracológica tenha sido previamente realizada neste sambaqui, ela se restringiu à análise de sedimentos da camada de cobertura, tendo oferecido resultados inéditos sobre o paleoambiente local durante o período de ocupação (Scheel-Ybert 2001). A análise de carvões de uma área funerária do sítio, 
proposta deste trabalho, visa esclarecer questões sobre o uso de vegetais e o uso do fogo em contexto ritual, buscando contribuir para uma melhor compreensão das relações sócio-culturais estabelecidas pelos grupos sambaquieiros com o ambiente por eles ocupado.

\section{Área de Estudo}

O sítio Jabuticabeira-II está localizado no município de Jaguaruna, litoral Sul do Estado de Santa Catarina, georreferenciado pelas coordenadas -28 35'25,06156" e -48 57'36,33285" (Fig. 1). Este sambaqui está situado no flanco de uma paleoduna, a cerca de $1 \mathrm{~km}$ da margem sudoeste da lagoa Garopaba do Sul e cerca de 6 $\mathrm{km}$ do mar.

É um dos sítios mais bem datados do Brasil. Atualmente, existem 46 datações disponíveis (Assunção 2010), provenientes de diferentes fontes orgânicas resgatadas durante as intervenções realizadas ao longo de anos de pesquisas. Interpretações com base nestas datações têm contribuído para discutir diversas questões a respeito dos processos de formação do sítio e de seus ritmos de construção (Simões 2007), o período de ocupação (Fish et al. 2000) e variações paleoambientais (Scheel-Ybert et al. 2003; Kneip 2004), além de inferências sobre contatos transculturais (Gaspar, 2000; DeBlasis et al. 2007). As datas disponíveis mostram uma ocupação contínua do sítio entre $2880 \pm 75$ anos BP (3209-2779 anos cal BP) e 1805 \pm 65 anos BP (1864-1534 anos cal BP).

Sua estratigrafia é bastante complexa, caracterizada por uma intensa alternância de camadas sobrepostas e imbricadas umas nas outras (Fish et al. 2000) (Fig. 2). As camadas de conchas e areia não apresentam vestígios tais como fogueiras ou buracos de estaca; artefatos são raramente encontrados, e quando isso ocorre se dá de forma isolada. Estas camadas foram denominadas "camadas de preenchimento", "mounds de preenchimento", ou "camadas de cobertura", caracterizando-se por cobrir perfeitamente cada camada funerária. Já as camadas funerárias são formadas por um sedimento escuro, rico em restos orgânicos e, em geral, não ultrapassam cerca de $20 \mathrm{~cm}$ de espessura. Algumas delas expõem certo padrão de aplainamento (salvo algumas exceções), ao contrário das camadas do pacote

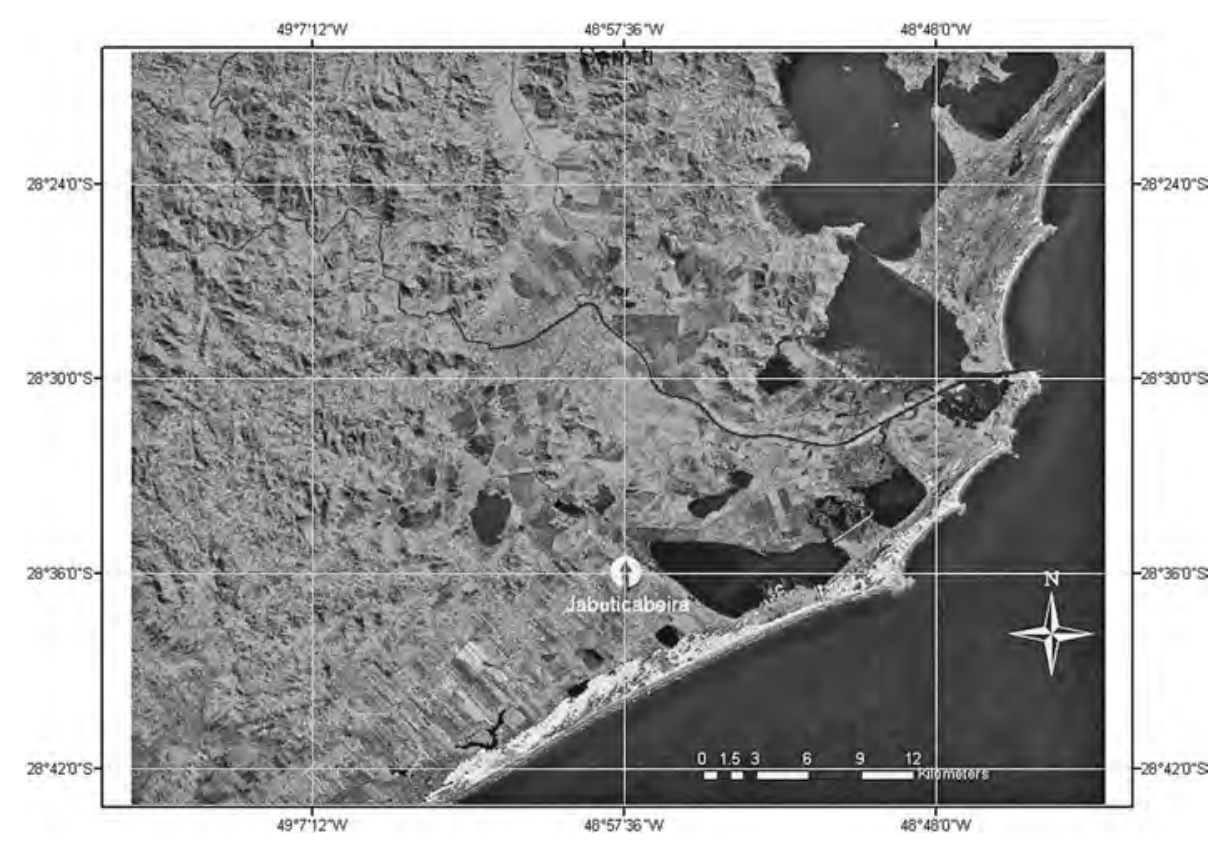

Fig. 1. Localização geográfica do sítio. Base Cartográfica Landsat 5 (1984) (Lucas B. Garcindo). 
Processos de formação do sambaqui Jabuticabeira-II: interpretações através da análise estratigráfica de vestígios vegetais carbonizados. R. Museu Arq. Etn., São Paulo, n. 21, p. 51-69, 2011.

conchífero, geralmente em forma de pequenas construções monticulares. Apresentam diversos sepultamentos e todo um aparato funerário, como marcas de estacas, estruturas de combustão, manchas de fogueira e artefatos associados.

Diversos enterramentos foram evidenciados ao longo dos 125 metros de perfis estudados, bem como das superfícies de escavação do sítio. Tanto os buracos de estacas como as fogueiras encontram-se geralmente associados aos sepultamentos. Acompanhamentos funerários, como instrumentos líticos, conchas, lápides, ossos de fauna, sugerem a realização de rituais mortuários. O sítio é interpretado como um local especialmente construído para a preservação dos corpos que, muito provavelmente, servia também como um marco territorial, visto o destaque que assume na paisagem (Fish et al. 2000; Klökler 2001, 2008; DeBlasis et al. 2007).

\section{Materiais e métodos}

A amostragem antracológica do sambaqui Jabuticabeira-II foi obtida a partir da escavação de um perfil da Trincheira 18 (T18), localizada no Locus I do sítio.

A parte superior do perfil, correspondendo à camada de cobertura, foi amostrada em níveis artificiais de $10 \mathrm{~cm}$ numa seção de $2 \mathrm{~m}$ de largura por $50 \mathrm{~cm}$ de profundidade, de 0,30 até $3,30 \mathrm{~m}$ de profundidade (Fig. 3). Os $30 \mathrm{~cm}$ superficiais deste perfil, compostos de terra preta, não foram amostrados devido à presença de bioturbações. A parte inferior do perfil, de 3,30 até 4,00 $\mathrm{m}$ de profundidade, no nível do solo atual, corresponde a uma camada funerária e foi escavada de acordo com a estratificação natural, coletando-se o sedimento das diferentes feições identificadas no campo (Fig. 4).

As amostras da camada funerária analisadas no presente trabalho, por sua vez, corresponderam estritamente às feições arqueológicas escavadas durante a coleta, e foram denominadas de acordo com um código alfa-numérico, pois elas não correspondem a uma sequência temporal. Vinte e três amostras foram analisadas e posteriormente reagrupadas segundo as feições arqueológicas, resultando em 15 amostras denominadas A1 a A15. A descrição destas e das

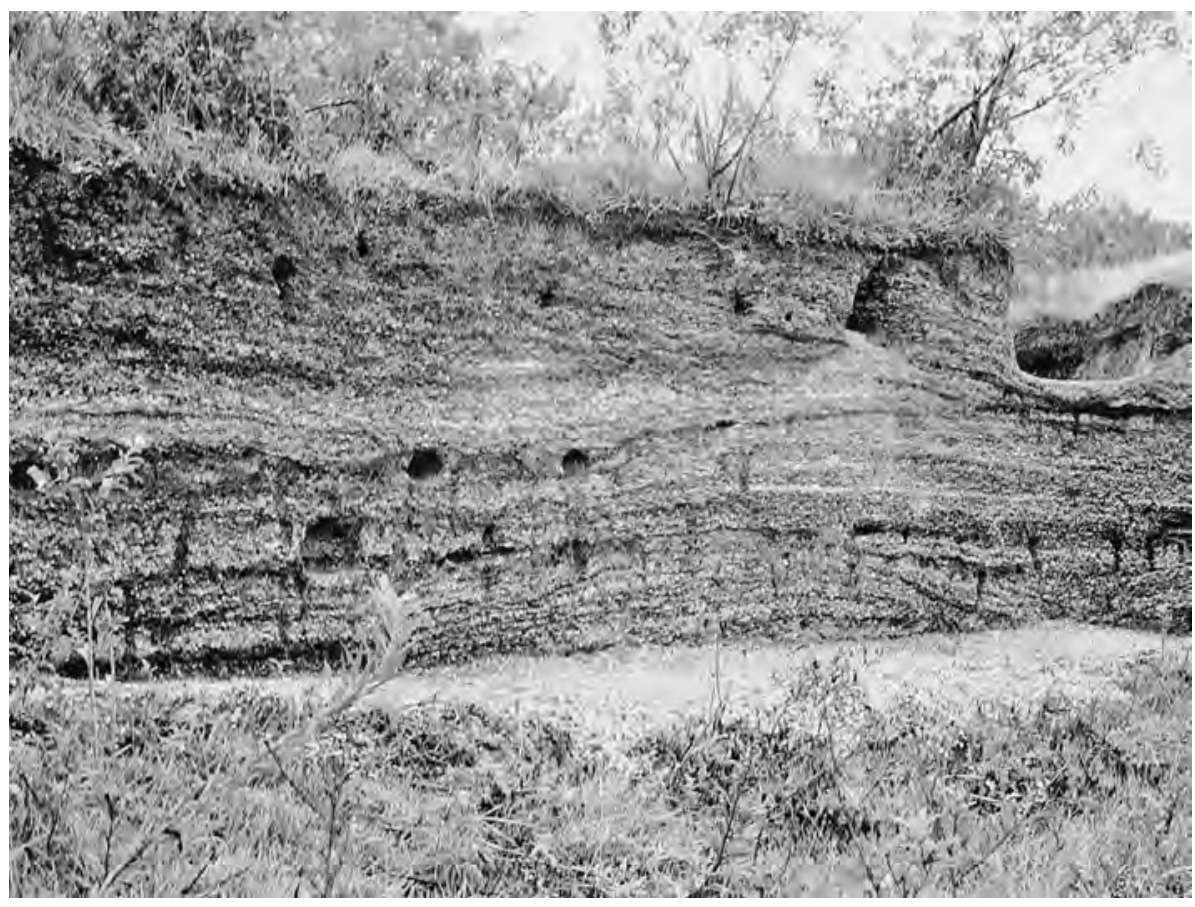

Fig. 2. Perfil estratigráfico do sítio Jabuticabeira-II. Locus 2 (foto G. Bianchini). 


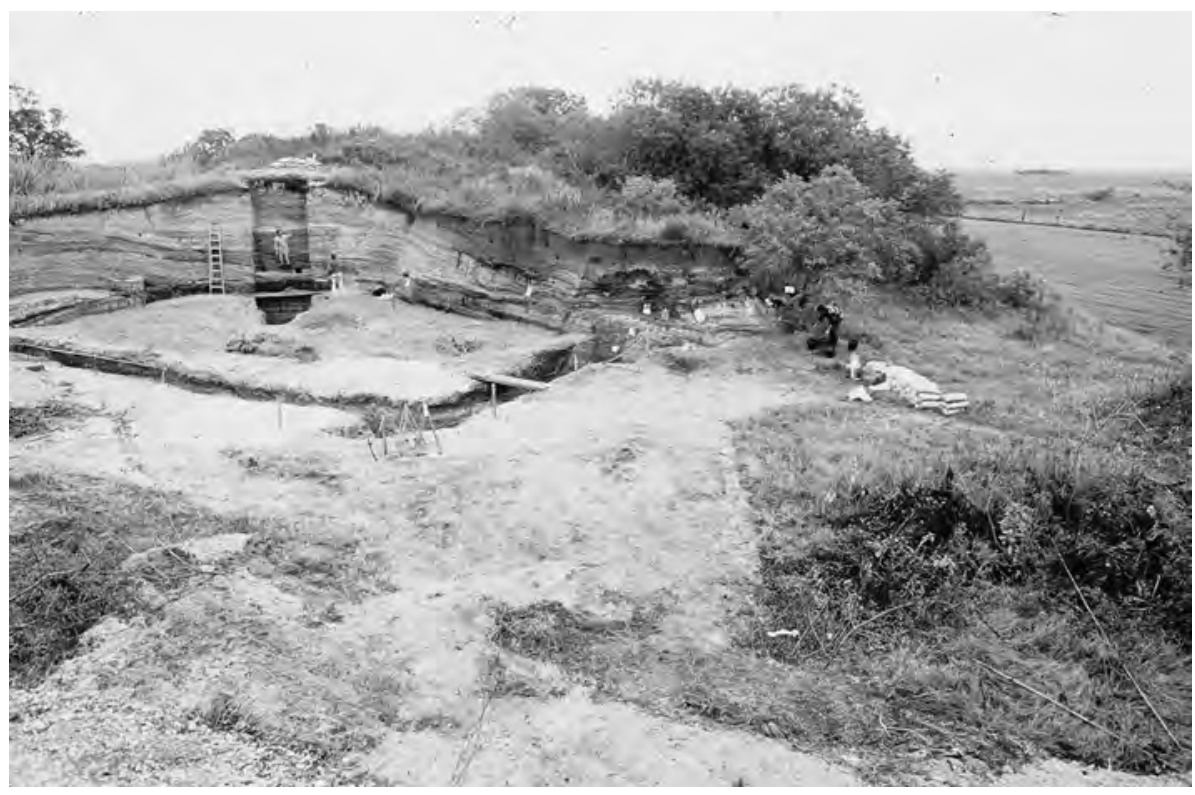

Fig. 3. Sítio Jabuticabeira-II. Aspecto do perfil da Trincheira 18, Locus 1, no qual foram realizadas as amostragens do "mound de cobertura" e da área funerária (foto MaDu Gaspar).

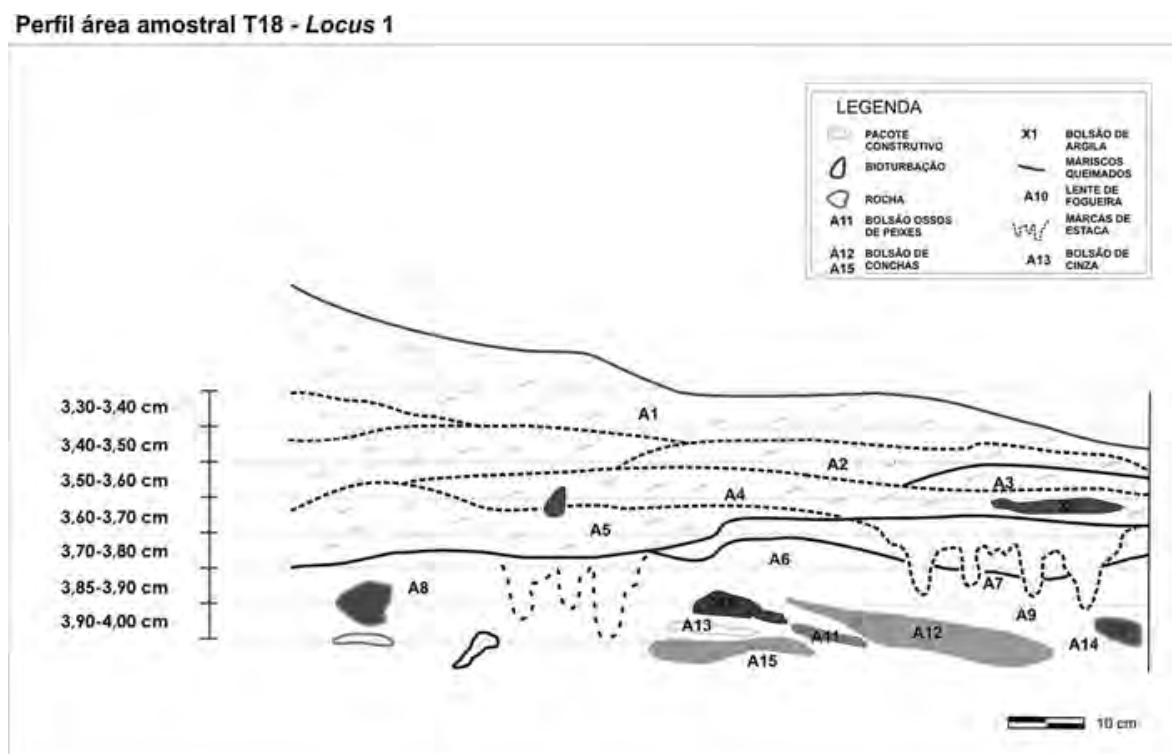

Fig. 4. Sítio Jabuticabeira-II, Locus 1, Trincheira T18. Perfil da área funerária indicando as principais feições e a distribuição das amostras em relação aos níveis artificiais previamente definidos (desenho e digitalização G. Bianchini.).

amostras do pacote de preenchimento é dada a seguir (Tabela 1).

Todo o sedimento retirado desta unidade de escavação foi coletado em baldes de tamanho padronizado e flotado em campo para recuperação dos carvões de acordo com a metodologia proposta por Scheel-Ybert et al. (2005). 
A identificação botânica dos carvões foi obtida pela análise da estrutura anatômica do lenho a partir da quebra manual dos fragmentos segundo os três planos fundamentais da madeira (transversal, longitudinal tangencial e longitudinal radial), em microscópio Zeiss de luz refletida com campo claro, campo escuro e contraste interferencial. Todos os fragmentos de carvão com mais de $4 \mathrm{~mm}$ de lado foram analisados. As descrições anatômicas seguiram os procedimentos e terminologias recomendados pela Associação Internacional de Anatomistas da Madeira (IAWA Committee 1989).

Para a determinação sistemática, comparou-se a estrutura anatômica dos fragmentos arqueológicos com amostras da coleção de referência de amostras atuais e com descrições e fotografias de obras de referência (Record e Hess 1943; Détienne e Jacquet 1983; Mainieri e Chimelo 1989). O processo de identificação foi subsidiado pelo uso do programa de identificação antracológica "Atlas Brasil" (Scheel-Ybert et al. 2006).

Diagramas antracológicos foram construídos com o programa C2 (Juggins 2007). A fim de permitir uma melhor discussão e interpretação dos dados, foram incluídos neste diagrama os dados anteriormente obtidos por Scheel-Ybert (2001) neste mesmo perfil, oriundos do pacote de preenchimento. Para isso, foi feito um re-tratamento dos dados, visto que as amostras analisadas pela autora continham muito poucos fragmentos, o que provocou uma variação aleatória das frequências relativas dos taxa analisados. Visando evitar esse efeito e tendo em vista a homogeneidade antracológica, os dados das amostras dos níveis artificiais foram reunidos, perfazendo amostras de 30 a $50 \mathrm{~cm}$ de espessura cada.

Análises estatísticas foram feitas com o uso do programa R (R Development Core Team 2007). A interpretação do diagrama e a caracterização do paleoambiente estudado foram feitas a partir da relação com o ambiente natural e com as associações vegetais atualmente conhecidas, confrontando-se dados da análise antracológica com estudos fitossociológicos atuais, conforme recomendado na literatura (Scheel-Ybert 1999; Pearsall 2000; Solari e Lehnebach 2004).

Tabela 1

\begin{tabular}{cl}
\hline Níveis/Amostras & \multicolumn{1}{c}{ Descrição } \\
\hline \hline 30-60 & $\begin{array}{l}\text { Areia fina de coloração cinza claro; presença de conchas fragmentadas e intei- } \\
\text { ras, em menor quantidade (Anomalocardia sp). }\end{array}$ \\
Co-100 & $\begin{array}{l}\text { Continuação da camada anterior. Presença de uma lente fina de areia escura } \\
\text { com fragmentos de mariscos queimados, conchas e carvão. }\end{array}$ \\
Areia, coloração cinza escuro; conchas fragmentadas e inteiras (Lucina sp e \\
Anomalocardia sp); mariscos. \\
140-180-220 & $\begin{array}{l}\text { Continuação da camada anterior. } \\
\text { Continuação da camada anterior. Presença de uma feição formada por conchas } \\
\text { fem linhas paralelas indicando pisoteio. }\end{array}$ \\
220-260 & $\begin{array}{l}\text { Areia, coloração cinza escuro; conchas fragmentadas (Anomalocardia sp); frag- } \\
\text { mentos de carvão; mariscos queimados; lentes de areia entremeadas às conchas } \\
\text { marcando superfícies temporárias. }\end{array}$ \\
& $\begin{array}{l}\text { Continuação da camada anterior. Presença de uma feição composta por maris- } \\
\text { cos queimados, fragmentados; argila queimada de coloração marrom-avermelha- } \\
\text { da; camadas de cinzas. }\end{array}$
\end{tabular}


Tabela 1 (cont.)

280-330 cos queimados, fragmentados; presença de ossos de peixes fragmentados; areia marrom clara e areia clara; fragmentos de carvão; superfícies temporárias menos pronunciadas.

Continuação da camada anterior. Camada branca de conchas muito fragmen-

330-340 A1 tadas (ca. $5 \mathrm{~cm}$ de espessura), localizada especialmente à direita do perfil, sendo que no centro do perfil foi verificado um pequeno bolsão de areia branca.

Camada de sedimento arenoso com conchas fragmentadas e alguns restos de

340-350 A2 peixes, contendo uma fina camada de sedimento preto de fogueira com conchas "queimadas" (avermelhadas). Presença de um buraco de animal a $50 \mathrm{~cm}$ da margem esquerda do perfil.

$350-360$

A3 Continuação da camada de sedimento arenoso e do sedimento preto de fogueira com conchas à direita do perfil.

A4 Sedimento de fogueira com alguns bolsões arenosos à esquerda do perfil.

Sedimento escuro com carvões, conchas, ossos de peixe e alguns bolsões are-

$360-370$ nosos. Presença de um bolsão de argila com muito sedimento concrecionado (cinzas? conchas calcinadas?). Presença de ostras, uma das quais com uma marca que pode indicar mangue. Seixo queimado.

A6 Continuação do sedimento preto com carvões; muitas conchas, muitos ossos de peixe; presença de fogueiras e de bolsões de conchas e ossos de peixe.

Sedimento mais claro com conchas e marcas de estaca a até $50 \mathrm{~cm}$ da direita do

$370-380$

A7 perfil. Presença de conchas avermelhadas (queimadas?); alguns bolsões de areia clara no meio das conchas.

Continuação do sedimento preto com carvões; muitas conchas, muitos ossos de

$380-390$ peixe. Presença de 1 ostra. Na base deste nível, à esquerda do perfil, uma grande pedra. No centro do perfil, presença de uma "estrutura funerária" sob uma camada de cinzas concrecionadas, à esquerda da qual ocorre uma grande fogueira.

Sedimento escuro da fogueira, com muito carvão, conchas e ossos de peixe.

A9 Presença de lascas térmicas, 1 ostra, e de uma pedra grande no canto direito do perfil, na base deste nível.

A10 Fogueira ao lado do sepultamento; muitos carvões.

A11 Bolsão de ossos de peixe entre duas camadas de cinzas. Presença de muitas barbatanas de peixes, aparentemente grandes, bem estruturadas.

A12 Camada de cinzas concrecionadas com marcas de estaca.

390-400 A13 Base da fogueira com bolsões de conchas.

A14 Bolsão de conchas à direita do perfil.

A15

Camada de conchas avermelhadas inteiras debaixo da camada de cinzas, aparentando um piso. Presença de 3 ostras grandes.

Tabela 1. Sítio Jabuticabeira-II, Locus 1, Trincheira T18. Descrição estratigráfica do perfil e características do sedimento amostrado. 
Processos de formação do sambaqui Jabuticabeira-II: interpretações através da análise estratigráfica de vestígios vegetais carbonizados. R. Museu Arq. Etn., São Paulo, n. 21, p. 51-69, 2011.

\section{Resultados e discussões}

Foram analisados ao todo 3.981 fragmentos de carvão, sendo 1.788 provenientes do pacote de preenchimento (Scheel-Ybert 2001) e 2.193 da camada funerária (Bianchini 2008). A grande maioria dos espécimes identificados corresponde a taxa encontrados nas várias formações vegetais que ocorrem atualmente na região (Fig. 5). As famílias Myrtaceae e Lauraceae foram as mais representativas, considerando-se tanto a riqueza (9 e 7 taxa, respectivamente) quanto os valores de dominância (100\%) e de freqüência relativa média (19 e 14\%, respectivamente).

$\mathrm{Na}$ camada de cobertura foram identificados 40 taxa distribuídos em 28 famílias (Scheel-Ybert 2001). Destaca-se neste nível a ocorrência de Patagonula americana (Boraginaceae), espécie característica da Floresta de Araucária, representada por um único indivíduo em toda a amostragem.

A análise da camada funerária permitiu a determinação de 116 taxa, distribuídos em 40 famílias botânicas. A riqueza florística destas amostras foi bastante grande, variando entre 30 a 50 taxa por amostra.

\section{Paleoambiente}

Os resultados apresentados indicam que o sítio Jabuticabeira-II estava localizado em um ambiente de Restinga, assim como registrado em estudos anteriores do mesmo sítio e em outros sítios do tipo sambaqui (Scheel-Ybert 2000, 2001; Scheel-Ybert; Dias 2007). Incluem-se neste macro-ambiente as variações fitofisionômicas de Restinga Aberta e Mata de Restinga, distintas entre si florística e fitossociologicamente, principalmente em função de caracteres edáficos.

A caracterização do ambiente durante o período de ocupação do sítio (2921-2357 a 1864-1534 anos cal BP) indicou a existência de uma vegetação relativamente "estável”, bastante semelhante àquela encontrada atualmente. Esta estabilidade já foi apontada em outros estudos para a região (Scheel-Ybert 2001), bem como para o Sudeste do país (Scheel-Ybert 2000; Scheel-Ybert e Dias 2007).
A grande proporção de espécies típicas da Mata Atlântica encontrada no registro antracológico sugere que esta formação ocorria em áreas relativamente próximas da costa, provavelmente em cotas mais elevadas, assim como atualmente. A presença destas espécies indica que estas áreas eram regularmente exploradas pelos ocupantes do Jabuticabeira-II, fazendo parte de sua área de captação de recursos habitual.

Outra característica vegetacional reproduzida no registro antracológico é a presença de poucas famílias representadas por um grande número de espécies (Myrtaceae, Lauraceae, Rubiaceae e Euphorbiaceae) e muitas famílias representadas por poucas espécies (e.g. Bignoniaceae, Moraceae, Nyctaginaceae, Verbenaceae). Segundo levantamentos fitossociológicos atuais realizados na região (Martins 2005; Rebelo 2006; Silva 2006), este é um padrão vegetacional característico do Sul do país (cf. Odum 1983; Reitz 1961 apud Araujo 2000).

Análises multivariadas previamente realizadas sobre levantamentos fitossociológicos de formações vegetais do Sul e do Sudeste do Brasil e sobre dados antracológicos de sambaquis do litoral do Estado do Rio de Janeiro mostraram que, apesar de todos os processos que intervêm desde a coleta da madeira até a análise da amostra, tais como as transformações físicas sofridas pela madeira durante a carbonização e pelos carvões durante os processos pós-deposicionais, o cortejo taxonômico obtido pela análise antracológica se aparenta muito ao de associações vegetais atuais (Scheel-Ybert 2000).

Estes resultados sugerem que a vegetação existente na área durante a ocupação sambaquieira era qualitativamente semelhante aos tipos de vegetação que ocorrem na região atualmente, e demonstram a estreita equivalência entre os dados antracológicos e aqueles obtidos a partir da vegetação atual, tanto em relação à composição taxonômica quanto à distribuição das espécies (Fig. 5).

\section{Processos de formação do Jabuticabeira-II}

A reunião das duas análises (Scheel-Ybert 2001; Bianchini 2008) demonstrou diferenças significativas entre os dois pacotes, assim como é evidenciado no contexto arqueológico. 


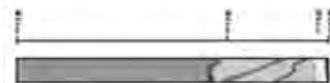

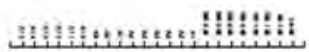

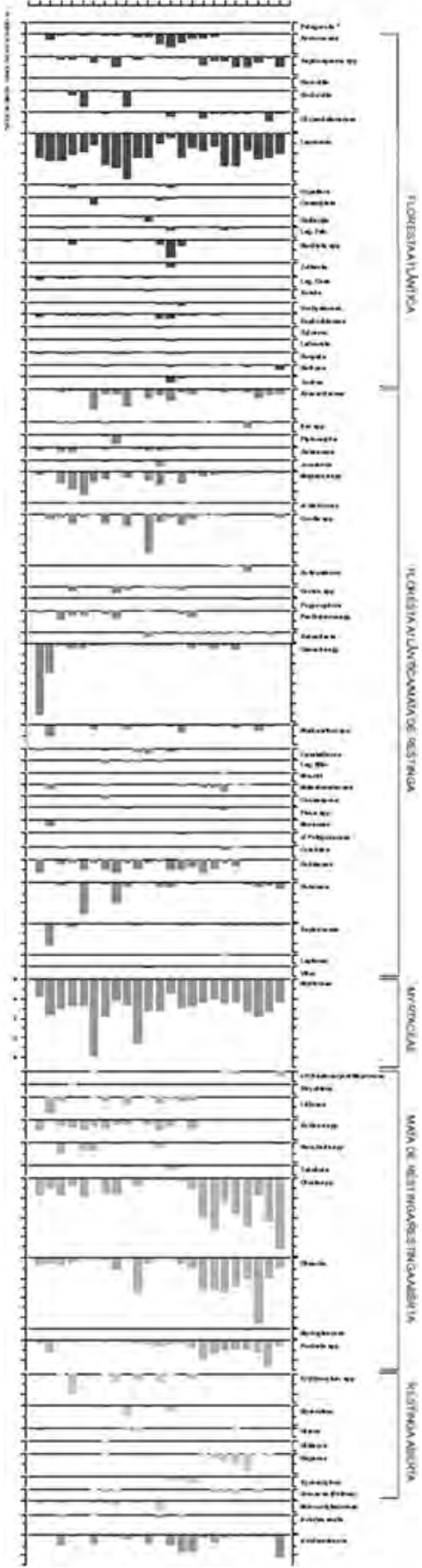

Fig. 5. Sítio Jabuticabeira-II, Locus 1, Trincheira T18. Diagrama antracológico completo.
As amostras da camada de cobertura que foram analisadas correspondem ao que se denomina em Antracologia de carvões dispersos. Estes carvões, geralmente muito abundantes no sedimento arqueológico, se originam do espalhamento de fragmentos residuais provenientes das diversas estruturas de combustão que existiram ao longo do tempo (Chabal 1992; Scheel-Ybert 2004).

As amostras de feições em contexto funerário, por sua vez, correspondem a carvões concentrados, os quais podem estar relacionados a atividades especializadas, por exemplo, materiais de construção ou objetos manufaturados queimados acidentalmente, produção de cerâmica ou atividades rituais. Frequentemente, no entanto, estes carvões se originam de fogos, fogões ou fogueiras que tiveram uma curta utilização no tempo, ou representam apenas os restos da última queima neles realizada. Em todos estes casos, estas amostras não são, geralmente, significativas da vegetação como um todo, mas podem conter importantes informações paleoetnobotânicas (Chabal 1992; Scheel-Ybert 2004).

O diagrama antracológico apresentado (Fig. 5) contém uma reunião de dados de duas análises diferentes: uma análise de amostras de carvões dispersos, correspondente a uma camada de cobertura de um perfil do Locus 1 (Trincheira T18), realizada por Scheel-Ybert (2001), e uma análise de amostras de carvões concentrados, correspondente a uma camada funerária do mesmo perfil (Bianchini 2008).

Cada "amostra" da camada de cobertura corresponde, na realidade, a reuniões de amostras de níveis artificiais de $10 \mathrm{~cm}$ de espessura, o que foi feito visando minimizar os efeitos estocásticos provocados pela análise de amostras muito pequenas na camada de cobertura. Por outro lado, cada amostra da camada funerária corresponde a uma fração de um nível artificial de $10 \mathrm{~cm}$, dado que neste caso foram amostradas feições arqueológicas individualizadas. Isto significa que, embora a quantidade de carvão por amostra pareça ser maior na camada de cobertura, na realidade é o inverso. De fato, se considerarmos os números absolutos, a camada de cobertura analisada, que alcança $3,00 \mathrm{~m}$ de espessura total, forneceu 1.788 fragmentos de 
Processos de formação do sambaqui Jabuticabeira-II: interpretações através da análise estratigráfica de vestígios vegetais carbonizados. R. Museu Arq. Etn., São Paulo, n. 21, p. 51-69, 2011.

carvão; enquanto a área funerária, que perfaz apenas $0,70 \mathrm{~m}$ de espessura, forneceu 2.193 fragmentos. Isto indica que as atividades de queima foram muito mais intensas na área funerária, fato que também é reconhecido no campo através de critérios arqueológicos.

Embora as amostras da camada funerária apresentem, algumas vezes, um número muito baixo de fragmentos, este fato é incontornável, pois neste caso trata-se de feições arqueológicas restritas.

Neste perfil, os carvões dispersos (camada de cobertura) apresentam uma diversidade significativamente inferior aos carvões concentrados (camada funerária). Enquanto na camada de cobertura a diversidade de espécies variou de 15 a 34 taxa, na camada funerária essa riqueza variou entre 30 a 50 taxa por amostra (Fig. 6). Tem-se como consequência uma inversão do padrão usualmente esperado em antracologia, de que uma maior diversidade específica seja sempre encontrada nos carvões dispersos (Badal Garcia 1992; Scheel-Ybert 2004).

Isto atesta a existência de uma diversidade vegetal comparável, ou mesmo superior à que é regularmente encontrada em estudos fitossociológicos atuais - como exemplo, em áreas de 1-1,5 ha de diferentes formações florestais onde foram amostrados 592 a 924 espécimes, encontrou-se de 31 a 54 taxa (Silva e Scariot 2004; Hack et al. 2005; Peixoto et al. 2005; Scherer et al. 2005).

Este fato pode ser compreendido se levarmos em conta que os carvões dispersos da camada de cobertura são provenientes de uma atividade doméstica contínua ao longo do tempo de deposição dos sedimentos. Villagrán (2008), ao analisar as camadas de cobertura da camada de terra preta, sugere que eles correspondem a uma deposição secundária, isto é, são materiais que foram originalmente reunidos em outro lugar e remobilizados por sobre a camada funerária com o propósito intencional de construção. Esta hipótese, provavelmente, pode ser estendida às camadas conchíferas de cobertura e explicaria a presença destes carvões dispersos.

A alta diversidade que caracteriza as amostras de carvões "concentrados" da camada funerária, por sua vez, indica que não se trata- vam de pequenas fogueiras utilizadas por um curto período, mas sim de intensas atividades de queima associadas às práticas rituais. A alta densidade de vestígios faunísticos evidenciada nestas camadas sugere, inclusive, que este material é provavelmente proveniente da realização de festins (Klökler 2008).

A análise de agrupamento pelo método de Ward demonstra claramente a diferença entre as duas camadas, separando as amostras em dois grandes grupos, um formado pelas amostras da camada de cobertura e o outro pelas amostras da camada funerária (Fig. 6).

A maior diversidade de espécies dentre as amostras da camada de cobertura foi verificada na amostra 220-260. Esta amostra corresponde a uma camada espessa de areia, com fragmentos de conchas (Anomalocardia sp), carvão, mariscos queimados e lentes de areia marcando superfícies temporárias (Simões 2007). A presença de superfícies temporárias sugere momentos de abandono do sítio, mas, por outro lado, a antracologia aponta momentos de intensa atividade, em razão da elevada diversidade.

Outras amostras com significativa diversidade foram 60-100, 180-220, 260-280 e 280-330. $\mathrm{Na}$ análise de agrupamento a reunião de 180 220 e 220-260 assim como de 60-100 e 280-330 corrobora a estreita similaridade entre elas. A similaridade entre as amostras 180-220 e 220-260 é mais facilmente entendida, em se tratando de amostras subsequentes. Mais ainda se levado em conta que as várias camadas que compõem a Trincheira 18, têm origem nos níveis superiores de seções adjacentes à direita do perfil e continuam diagonalmente em vários níveis artificialmente amostrados.

Entretanto, chama atenção a reunião da amostra 60-100 com 280-330 (Figs. 6 e 7). Que fatores de similaridade reuniriam duas amostras tão distantes entre si ao longo do perfil?

De acordo com a descrição estratigráfica, um elemento comum na constituição destas camadas, além da diversidade de carvões, é a presença de lentes de mariscos queimados. Parece haver, nestas amostras da camada de cobertura, uma estreita relação entre a presença de lentes de mariscos queimados e a diversidade de carvões. Essa relação pode indicar a ocorrência de uma 


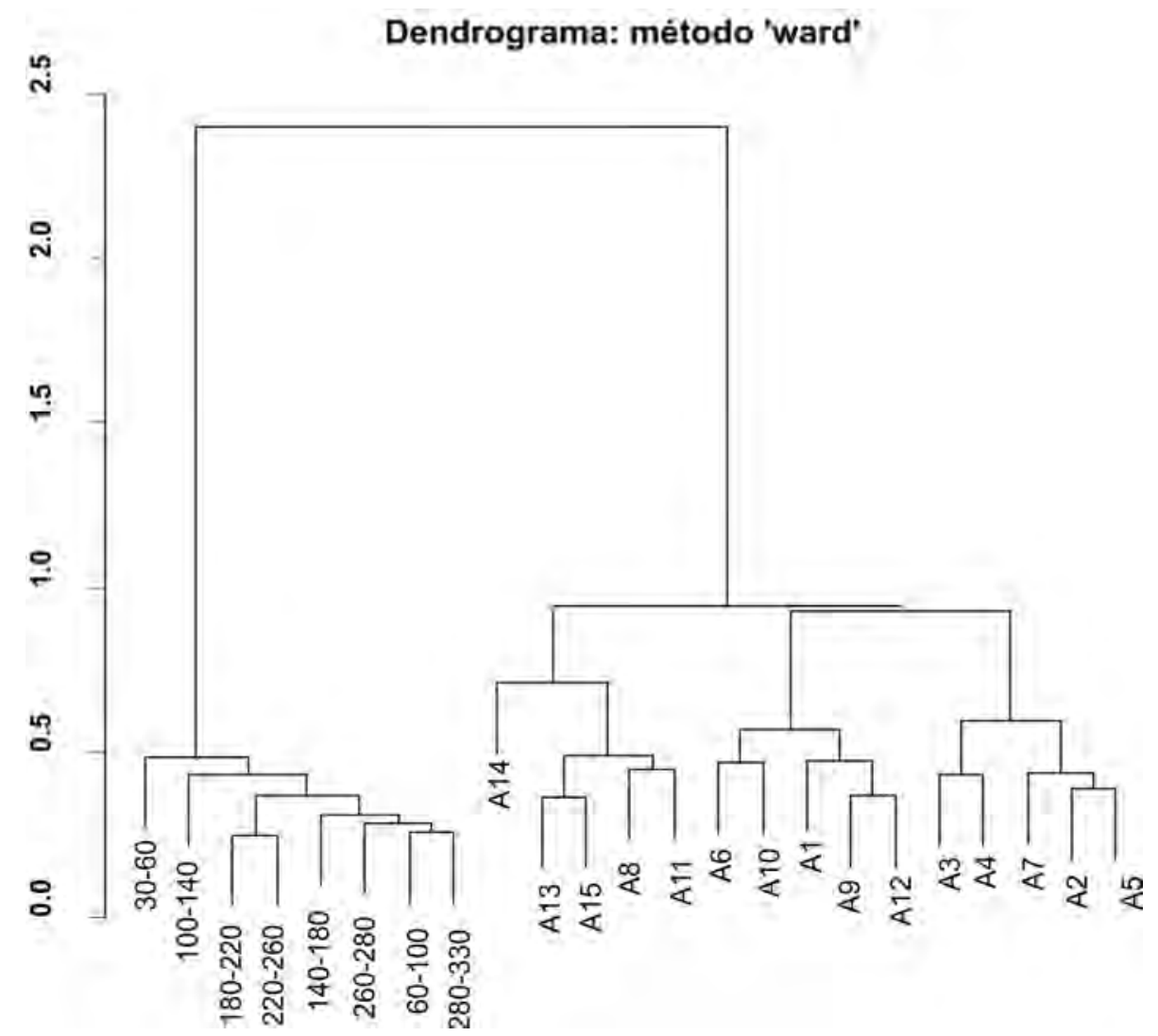

Fig. 6. Sítio Jabuticabeira-II, Locus 1, Trincheira T18. Agrupamento das amostras analisadas através do método Ward.

atividade especializada e de grande intensidade indicando momentos de revisitação. Estudos detalhados focando nestas estruturas do perfil poderão futuramente reforçar esta hipótese.

Por outro lado, na análise de agrupamento simples a amostra A1 é separada das amostras da camada funerária e agrupada às amostras da camada de cobertura (Fig. 7). Este método agrupa amostras pela máxima similaridade com qualquer outro ponto do grupo, diferente do anterior que minimiza a variância entre as amostras. Isso significa que, de modo geral, a amostra A1 se assemelha mais às amostras da camada de cobertura do que àquelas da camada funerária, o que concorda com as observações feitas no campo sobre a constituição estratigráfica dos sedimentos amostrados. Esta amostra corresponde a uma camada formada principalmente de conchas muito fragmentadas, com bolsões de areia branca, não apresentando estruturas de combustão bem marcadas, localizada logo abaixo da camada de mariscos queimados (Fig. 8). Esta análise de agrupamentos indica que não só sua caracterização estratigráfica, mas também a constituição do registro antracológico desta amostra é similar às amostras da camada de cobertura.

Outra hipótese é de que esta amostra possa estar relacionada a um evento funerário distinto, separado por uma camada de conchas pouco espessa, o que é bem provável dado o padrão imbricado destas camadas, o que muitas vezes dificulta sua delimitação com precisão.

De acordo com as características das feições descritas no campo, as amostras da camada funerária foram reunidas em três grupos, de acordo com sua composição e distribuição estratigráfica. 


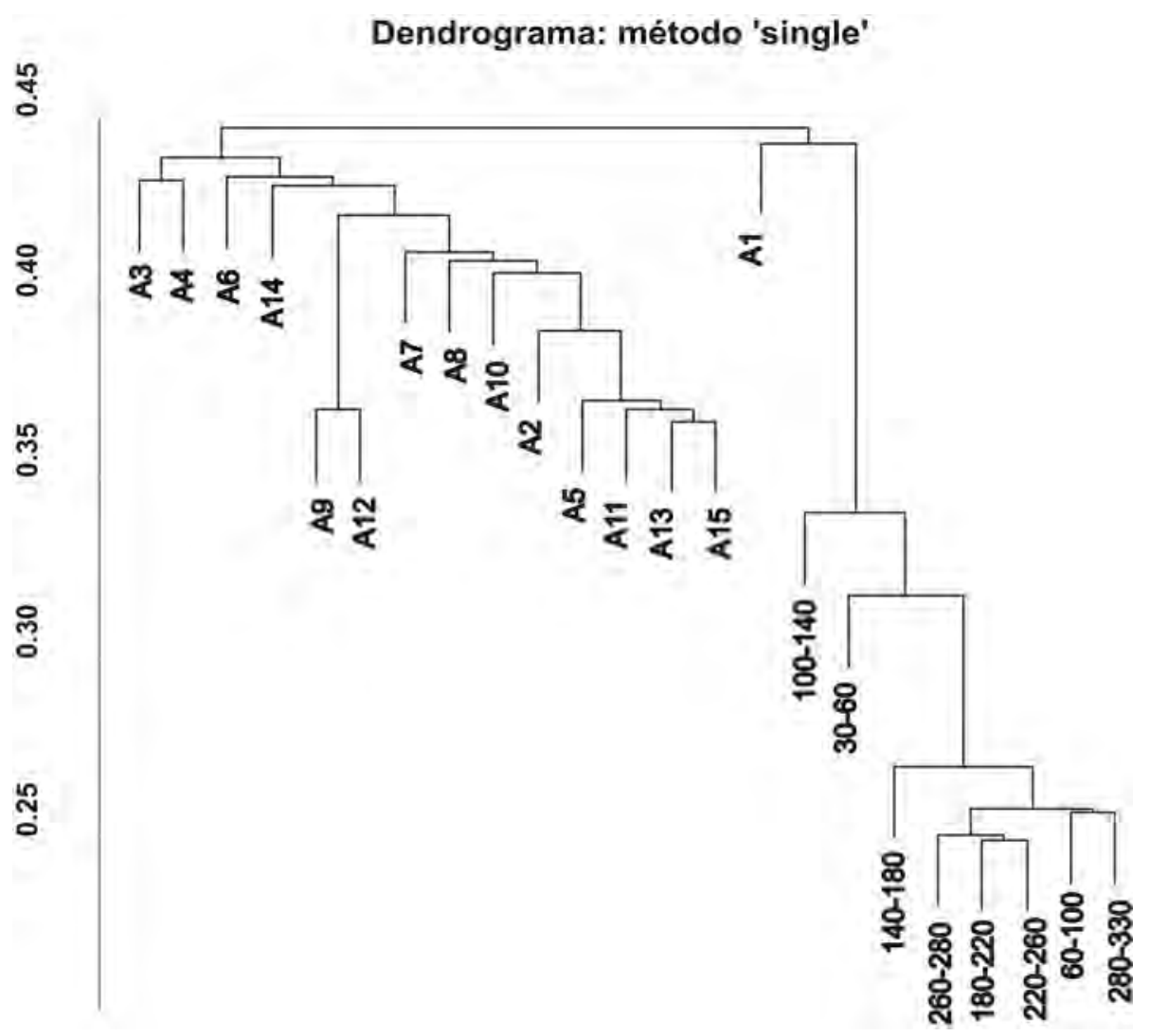

Fig. 7. Sítio Jabuticabeira-II, Locus 1, Trincheira T18. Análise de agrupamento das amostras analisadas segundo método 'single'.

O primeiro grupo é formado por amostras que apresentaram características semelhantes às amostras da camada de cobertura (A1-A3), o segundo foi definido como sendo uma área de transição (A4-A5, A7), e o terceiro como amostras da estrutura funerária propriamente dita (A6, A8-A15). Percebe-se na análise de correspondência simples (CA) que estes grupos foram similarmente reunidos de acordo com sua composição taxonômica, e que, assim como nas análises de agrupamento, há uma separação nítida entre as amostras da camada de cobertura e as da camada funerária (Fig. 9).

A amostra A7, inicialmente classificada como parte da camada funerária, se agrupa coerentemente, na análise de correspondência, às amostras da área de transição. Esta amostra corresponde a uma camada de sedimento mais claro com conchas, com alguns bolsões de areia clara, pouco material arqueológico e marcas de estaca. A presença de marcas de estaca de fato a define como parte de uma área funerária, mas trata-se provavelmente de outra área, a qual se situa estratigraficamente acima da área funerária estudada, para dentro do perfil. No entanto, com exceção deste fato, a amostra não contém material relacionado com o ritual funerário em si, e provavelmente por isso sua composição se aproxima da amostras da área de transição.

Esta amostra apresentou uma frequência significativamente alta de Lauraceae, em torno de $26 \%$. Este taxon é constante ao longo de todo o registro antracológico, entretanto a frequência de indivíduos nesta amostra se destaca em relação às demais. Pode-se propor, em consequência, que a composição da amostra A7 esteja apontando para uma seleção de espécies de Lauracae para a fabricação destas estacas. Diversos motivos, tanto funcionais quanto simbólicos, podem ter levado à seleção deste taxon para 


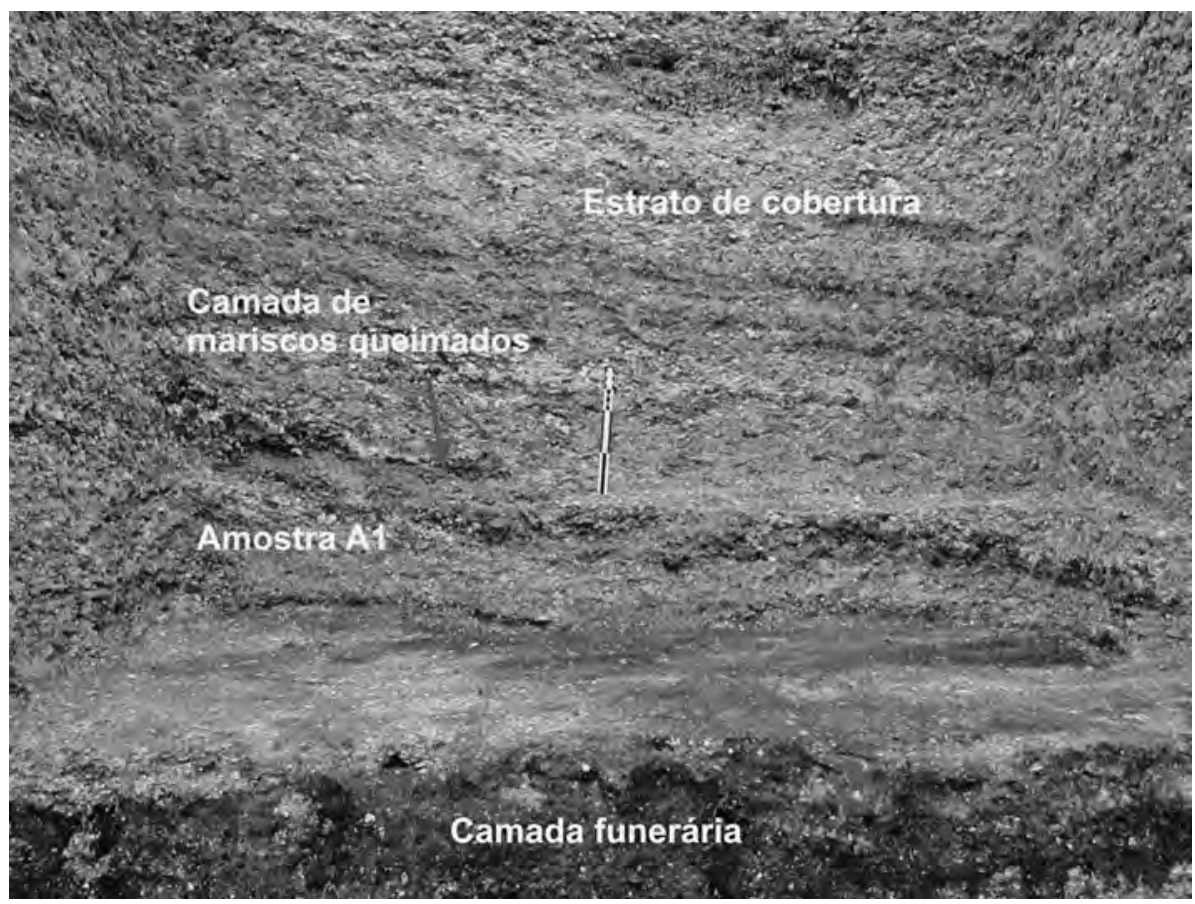

Fig. 8. Sítio Jabuticabeira-II, Locus 1, Trincheira T18. Aspectos da estratigrafia da camada de cobertura e da amostra A1. Note-se a camada de mariscos queimados acima da amostra A1 (foto R. Scheel-Ybert).

compor o aparato funerário, como discutido por Bianchini et al. (2007). O aumento da frequência destes carvões pode estar relacionado à queima da estrutura funerária erigida.

Os estudos antracológicos realizados em sambaquis anteriormente indicaram que, entre grupos sambaquieiros, a coleta de lenha para uso doméstico era baseada na coleta aleatória de madeira morta (Scheel-Ybert 2000, 2001; Scheel-Ybert e Dias 2007). Por outro lado, os resultados obtidos a partir da análise da camada funerária do Jabuticabeira-II apontam para a prática de coleta seletiva de algumas espécies. Estes dois resultados, no entanto, não se contrariam mutuamente na medida em que os dados previamente obtidos se referem a estudos de carvões dispersos, provavelmente de origem doméstica, enquanto as amostras analisadas no sítio Jabuticabeira-II são provenientes de um contexto funerário, ritual. É de se esperar que todos os elementos que fazem parte do ritual funerário sejam cuidadosamente escolhidos, ao contrário do que ocorre com a lenha de uso doméstico.
Os resultados obtidos a partir da análise da camada de cobertura do mesmo perfil do Jabuticabeira-II, inclusive, corroboram esta afirmação, na medida em que nenhum indício claro de seleção pode ser percebido neste contexto.

A proporção de sementes e coquinhos também varia bastante nas amostras. Em A6, A13, A14 e A15 há um aumento significativo na proporção de coquinhos em relação às sementes. Este aumento não pode ser explicado por uma possivel preservação diferencial (fragmentos de carvão mais frágeis e fragmentos de coquinhos mais resistentes), pois a abundância relativa destes elementos foi calculada através da relação coquinhos-sementes/carvão. $\mathrm{O}$ uso do número de fragmentos de carvão de cada nível no denominador, ao invés de porcentagens simples, visa precisamente controlar a preservação diferencial (Miller 1988).

A presença recorrente de coquinhos no registro arqueológico de diversos sítios indica que a utilização deste recurso era comum entre diversos grupos (Morcote-Rios e Bernal 2001). 


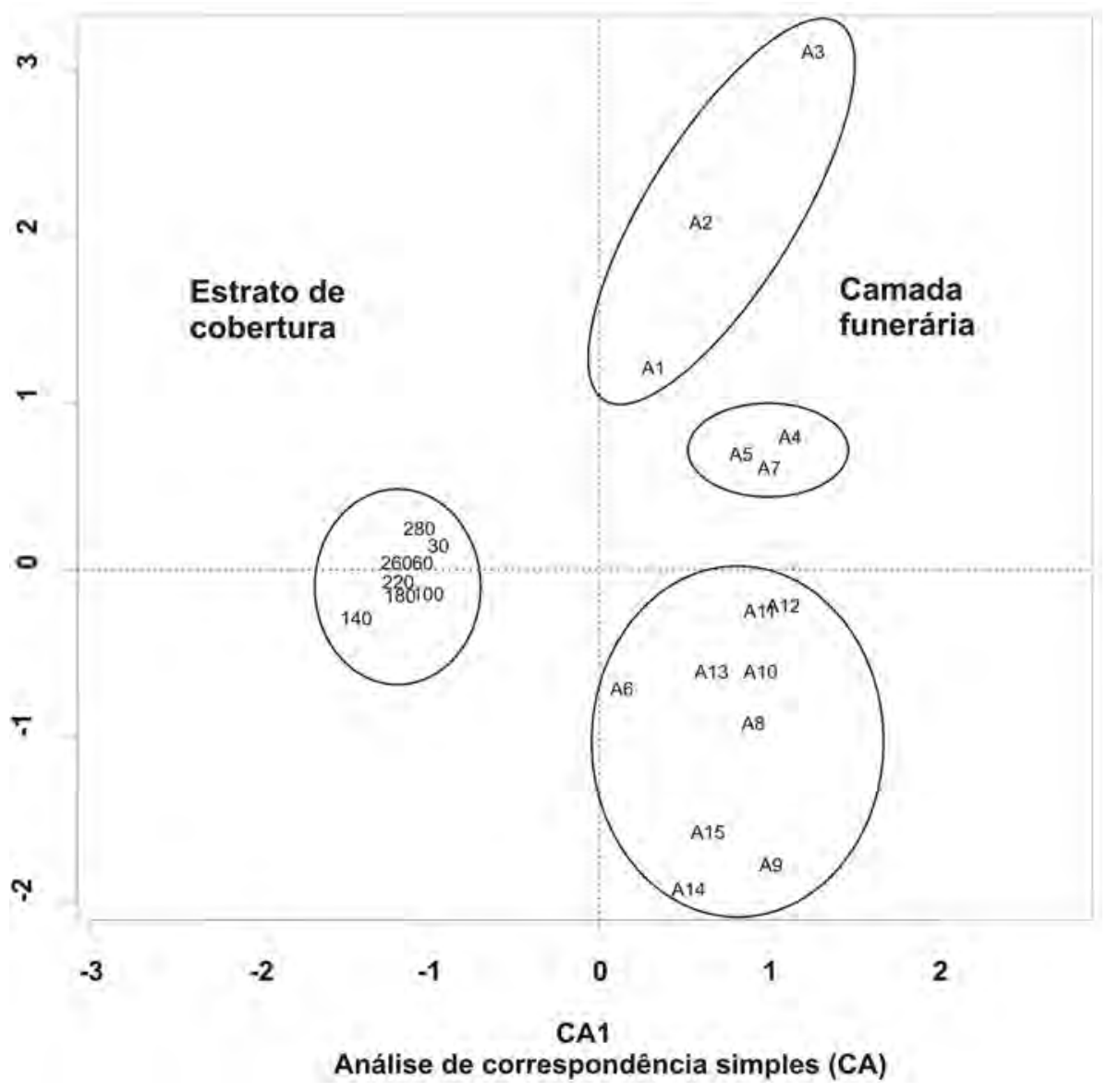

Fig. 9. Sítio Jabuticabeira-II, Locus 1, Trincheira T18. Análise de Correspondência Simples (CA) das amostras da camada de cobertura e área funerária.

Dentre as amostras que apresentaram proporções de coquinhos significativas, A6 é uma amostra de sedimento de fogueira com bolsões de conchas, A13 uma amostra de sedimento da base da fogueira com bolsão de conchas, A14 um bolsão de conchas e A15 um piso de conchas. Parece haver uma relação direta entre bolsões de conchas e aumento na proporção de coquinhos nas amostras desta camada funerária. Seu significado, entretanto, seja ele investido de sentidos simbólicos, ou meramente circunstancial, demanda confirmação através do estudo de outros casos semelhantes.

Teriam estes sambaquieiros queimado coquinhos em fogueiras específicas com o objetivo de um fogo duradouro, já que o fruto oleaginoso é um excelente combustível, utilizado atual- mente com este propósito por diferentes culturas (Morcote-Rios e Bernal 2001)? E qual teria sido a relação destes coquinhos com os bolsões de conchas? Talvez se tivesse tratado de parte de uma estrutura singular, como algum tipo específico de oferenda. Entretanto, os dados ainda insuficientes não nos permitem responder a estas questões.

Diante do que foi discutido, percebe-se que há uma relação entre determinados tipos de estruturas arqueológicas da camada funerária e vestígios vegetais singulares, demonstrando fortes indícios de seleção. Neste sentido, são exemplos a amostra A7, apresentando marcas de estacas e elevada porcentagem de Lauraceae, as amostras de sedimento de fogueira, A8 e A9, com significativa proporção de sementes, e as 
amostras dos bolsões de conchas A13, A14 e A15, com elevadas proporções de coquinhos.

Além disso, a frequência de fragmentos de ramos em algumas amostras é outro dado interessante. Em antracologia, é possível distinguir os fragmentos de ramos através da observação da curvatura dos anéis de crescimento, bem como do ângulo formado entre os raios (Ludemann 2005). Através destes dados podem ser definidas classes de diâmetro dos fragmentos que, por sua vez, correspondem aos diâmetros dos troncos ou ramos das árvores utilizadas. Este não foi um dos objetos de estudo durante a análise dos fragmentos do Jabuticabeira-II, porém a presença de fragmentos de ramos com diâmetro muito pequenos $(<5 \mathrm{~cm}$ de diâmetro) não passou desapercebida.

Fragmentos de ramos estão presentes em $87 \%$ das amostras da camada funerária. Apesar da presença de ramos ter se mantido constante, as proporções sofreram variações entre as diferentes amostras (Fig. 10). As amostras A10 e A11 apresentaram elevadas proporções de ramos, correspondendo a $11 \%$ e $10 \%$ dos fragmentos analisados respectivamente. Estas amostras equivalem a uma estrutura de fogueira ao lado do sepultamento e a um bolsão de ossos de peixes respectivamente. Assim como A11, a amostra X2 também corresponde a um bolsão de ossos de peixes. Nesta amostra a proporção de ramos foi em torno de $43 \%$ dos fragmentos. Mesmo que esta frequência tão alta deva ser tomada com prudência, em razão do pequeno número de fragmentos analisados nesta amostra, ainda assim as proporções de ramos são bastante representativas e podem estar indicando um uso intenso deste material em algumas fogueiras.

Ainda que, em alguns destes casos, a hipótese de seleção exija dados mais consistentes, a presença significativa de determinados vegetais em feições arqueológicas específicas associadas à estrutura funerária provavelmente revela um ordenamento ritual. A frequência de vestígios vegetais, seja compondo parte de oferendas e/ ou festins, seja de fogueiras específicas ou de estruturas, demonstra que eles exerceram um papel importante nas atividades funerárias do sambaqui Jabuticabeira-II, tanto quanto os vestígios de conchas, de ossos de peixes ou de qualquer outro artefato.

\section{Conclusões}

Os resultados obtidos tanto a partir das amostras da camada de cobertura quanto das amostras da camada funerária indicam que não havia seleção de lenha de "uso geral", e que uma grande diversidade de espécies era utilizada. No entanto, há indícios que sugerem a ocorrência de seleção de alguns elementos relacionados ao ritual funerário. Ainda que, em alguns destes casos, esta hipótese ainda precise ser testada, a presença significativa de determinados vegetais em feições arqueológicas específicas associadas à

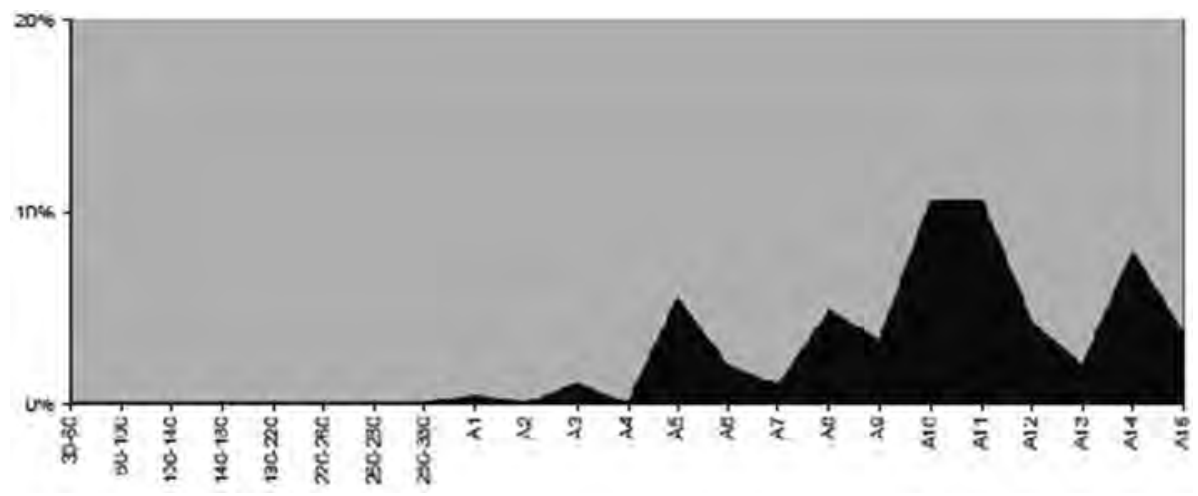

Fig. 10. Sítio Jabuticabeira-II, Locus 1, Trincheira T18. Proporção de ramos em relação ao número de fragmentos de carvão. Note que estes elementos não foram quantificados nas amostras da camada de cobertura, aonde eles ocorreram em porcentagens não significativas. 
estrutura funerária provavelmente reproduz um ordenamento ritual.

De modo geral, os dados obtidos a partir da análise antracológica sugerem que houve uma série de atividades ordenadas e intensas de mobilização, não só para a construção dos mounds funerários propriamente ditos, mas também no que se refere a aspectos como coleta de lenha, coleta e colocação das estacas e mobilização em relação à coleta das frutas e demais alimentos e/ ou oferendas envolvidas no ritual funerário.

Estes resultados demonstram que os vestígios de carvão podem fornecer valiosas informações sobre as práticas culturais dos grupos pretéritos, da mesma forma que todos os vestígios comumente utilizados pela arqueologia. Embora estejam estritamente relacionados ao uso do fogo (ritual/doméstico), estes elementos são produto de atividades específicas e culturalmente estabelecidas que ocorreram em determinados tempo e espaço e portanto refletem o movimento de pessoas assim como a difusão de idéias.

A frequência de vestígios vegetais, seja compondo parte de oferendas e/ou festins, seja de fogueiras específicas ou de estruturas, demons- tra que eles exerceram um papel importante nas atividades funerárias do Jabuticabeira-II, tanto quanto os vestígios de conchas, de ossos de peixes ou de qualquer outro artefato, e por este motivo os carvões devem ser estudados e interpretados como cultura material.

A análise antracológica de uma camada funerária do Jabuticabeira II demonstrou diferenças significativas entre as camadas de cobertura e as camadas funerárias, indicando a presença de determinados vegetais em feições arqueológicas específicas estritamente relacionadas à camada funerária. Estas evidências somadas aos resultados obtidos ao longo de mais de dez anos de pesquisas neste sítio reforçam o modelo interpretativo para o sambaqui enquanto estrutura funerária.

\section{Agradecimentos}

Este trabalho é parte da dissertação de Mestrado da primeira autora no Programa de Pós-Graduação em Arqueologia do Museu Nacional/UFRJ, e contou com apoio financeiro da FAPESP, CNPq e FAPERJ.

BIANCHINI, G.F.; GASPAR, M.D.; DEBLASIS, P.; SCHEEL-YBERT, R. Formation processes of sambaqui Jabuticabeira-II: stratigraphic interpretations through analysis of charred plant remains. R. Museu Arq. Etn., São Paulo, n. 21, p. 51-69, 2011.

Abstract: This paper presents the anthracological analysis of a funerary area from Jabuticabeira-II site, which is compared to the results of the analysis of the covering layer from the same profile accomplished by Scheel-Ybert (2001). All sediment samples were collected according to the archaeological features. The botanical identification of the fragments was performed under a microscope in reflected light by wood anatomy analysis. Significant differences were observed between the covering layer and the funerary area. Evidences suggest the occurrence of selection of some elements related to the funerary ritual.

Keywords: Funerary ritual - Charcoal - Anthracology - Shellmound. 


\section{Referências bibliográficas}

AFONSO, M.C.; DEBLASIS, P.A.D.

1994 Aspectos da formação de um grande sambaqui: alguns indicadores em Espinheiros II, Joinville. Revista do Museu de Arqueologia e Etnologia, 4: 21-30.

ARAUJO, D.S.D.

2000 Análise florística e fitogeográfica das restingas do Estado do Rio de Janeiro. Tese de Doutorado. Rio de Janeiro, PPG Ecologia, UFRJ.

ASSUNÇÃO, D.

2010 Sambaquis da Paleolaguna de Santa Marta: em busca do contexto regional no litoral sul de Santa Catarina. Dissertação de Mestrado. São Paulo, MAE- USP.

BADAL GARCIA, E.

1992 L'anthracologie préhistorique: à propos de certains problèmes méthodologiques. Bulletin de la Société Botanique de France, Actual. bot., 139 (2/3/4): 167-189.

BANDEIRA, D.R.

1992 Mudança na estratégia de subsistência do sítio arqueológico Enseada I: Um estudo de caso. Dissertação de Mestrado. São Paulo, MAE- USP.

BARBOSA, M.

2001 Espaço e organização social do grupo construtor do sambaqui IBV-4, RJ. São Paulo. Dissertação de Mestrado. São Paulo, MAE-USP.

BIANCHINI, G.F.

2008 Fogo e Paisagem: evidências de práticas rituais e construção do ambiente a partir da análise antracológica de um sambaqui no litoral sul de Santa Catarina. Dissertação de Mestrado. Rio de Janeiro, Museu Nacional-UFRJ.

BIANCHINI, G.F.; SCHEEL-YBERT, R.; GASPAR, M.D.

2007 Estaca de Lauraceae em contexto funerário (sítio Jaboticabeira-II, Santa Catarina, Brasil). Revista do Museu de Arqueologia e Etnologia, 17: 223-229.

CHABAL, L.

1992 La représentativité paléo-écologique des charbons de bois archéologiques issus du bois de feu. Bulletin de la Société Botanique de France, Actual. bot., 139 (2/3/4): 213-236.

DE MASI, M.N.

2001 Pescadores coletores da costa sul do Brasil. Pesquisas, sér. Antropologia, 57: 1-136.
DEBLASIS, P.A.D.; FISH, S.K.; GASPAR M.D. ; FISH, P.R.

1998 Some references for the discussion of complexity among the Sambaqui moundbuilders from the southern shores of Brazil. Revista de Arqueologia Americana, 15: 75-105.

DEBLASIS, P.A.D.; KNEIP, A.; SCHEEL-YBERT, R.; GIANNINI, P.C.; GASPAR,M.D.

2007 Sambaquis e paisagem: dinâmica natural e arqueologia regional no litoral do sul de Santa Catarina. Arqueologia Sul-Americana, 1 (3): 29-61.

DÉTIENNE, P.; JACQUET, P.

1983 Atlas d'identification des bois de l'Amazonie et des régions voisines. Centre Technique Forestier Tropical.

FIGUTI, L.

1993 O homem pré-histórico, o molusco e o sambaqui: considerações sobre a subsistência dos povos sambaquieiros. Revista do Museu de Arqueologia e Etnologia, 3: 67-68.

FISH, S.; DEBLASIS, P.; GASPAR, M.D.; FISH, P.

2000 Eventos incrementais na construção de sambaquis, litoral sul do Estado de Santa Catarina. Revista do Museu de Arqueologia e Etnologia,10: 69-87.

GASPAR, M.D.

1991 Aspectos da organização social de um grupo pescador - coletor - caçador: Região compreendida entre a Ilha Grande e o delta do Paraíba do Sul, Rio de Janeiro. Tese Doutorado. São Paulo, FLCH-USP.

1996 Análises das datações radiocarbônicas dos sítios de pescadores, coletores e caçadores. Boletim do Museu Paranaense Emilio Goeldi, sér. Ciências da Terra, $8: 81-91$.

1998 Considerations of the sambaquis of the Brazilian coast. Antiquity, 72: 592-615.

2000 Sambaqui: arqueologia do litoral brasileiro. Rio de Janeiro: Jorge Zahar.

2003 Aspectos da organização social de pescadores-coletores: região compreendida entre a Ilha grande e o delta do Paraíba do Sul, Rio de Janeiro. Pesquisas, 59: 1-163.

HACK, C.; LONGHI, S.J.; BOLIGON, A.A.; MU. RARI, A.B.; PAULESKI, D.T.

2005 Análise fitossociológica de um fragmento de floresta estacional decidual no município de Jaguari, RS. Ciência Rural, 35 (5): 1083-1091. 
Processos de formação do sambaqui Jabuticabeira-II: interpretações através da análise estratigráfica de vestígios vegetais carbonizados. R. Museu Arq. Etn., São Paulo, n. 21, p. 51-69, 2011.

IAWA Committee.

1989 IAWA list of microscopic features for hardwood identification. Wheeler, E.A.; Baas, P.; Gasson, P.E. (Eds.) IAWA Bulletin, n.s., 10 (3): 219-332.

JUGGINS, S.

2007 C2 Version 1.5. Software for ecological and palaeoecological data analysis and visualisation. Newcastle University, Newcastle upon Tyne, UK. In: http://www. campus.ncl.ac.uk/staff/Stephen.Juggins/ software/C2Home.htm

KLÖKLER, D.M.

2001 Construindo ou Deixando um Sambaqui? Análise de sedimentos de um sambaqui do litoral meridional brasileiro - processos formativos. Região de Laguna-SC. Dissertação de Mestrado. São Paulo, FFLCH-USP.

2008 Food for body and soul: mortuary ritual in shell mounds (Laguna - Brazil). Tese de Doutorado. Universidade do Arizona.

KNEIP, A.

2004 O Povo da Lagoa: uso do SIG para modelamento e simulação na área arqueológica do Camacho. Tese Doutorado. São Paulo, FFLCH-USP.

LUDEMANN, T.

2005 Experimental charcoal burning with special regard to anthracological wood diameter analysis. Proceedings of the Third International Meeting of Anthracology Lecce, Italy. British Archaeological Reports. Int. Series. 1-16.

MAINIERI, C.; CHIMELO, J.P.

1989 Fichas de características das madeiras brasileiras. 2 a ed. São Paulo: IPT.

MARTINS, R.

2005 Florística, estrutura fitossociológica e interações interespecíficas de um remanescente de Floresta Ombrófila Densa como subsídio para recuperação de áreas degradadas pela mineração de carvão, Siderópolis, SC. Dissertação de Mestrado. Florianópolis, UFSC.

MILLER, N.F.

1988 Ratios in paleoethnobotanical analysis. In: Hastorf, C.A.; Popper, V.S. (Eds.) Current Paleoethnobotany: Analytical methods and cultural interpretation of archaeological plant remains. Chicago/London, The University of Chicago Press: 72-85.

MORCOTE-RÍOS, G.; BERNAL, R.

2001 Remains of Palms (Palmae) at Archaeologi- cal Sites in the New World: a Review. The

Botanical Review, 67 (3): 309-350.

ODUM, E.P.

1983 Ecologia. Editora Guanabara. Rio de Janeiro. PEARSALL, D.M.

2000 Paleoethnobotany: A handbook of procedures. 2nd edition. San Diego: Academic Press.

PEIXOTO, G.L.; MARTINS, S.V.; SILVA, A.F. ; SILVA, E.

2005 Estrutura do componente arbóreo de um trecho de Floresta Atlântica na Área de Proteção Ambiental da Serra da Capoeira Grande, Rio de Janeiro, RJ, Brasil. Acta Botanica Brasilica, 19 (3): 539-547.

R DEVELOPMENT CORE TEAM.

2007 R: A language and environment for statistical computing. R. Foundation for Statistical Computing, Vienna, Austria. ISBN 3-900051-07-0, URL http://www.R-project.org.

REBELO, M.A.

2006 Florística e fitossociologia de um remanescente florestal ciliar: subsídio para a reabilitação da vegetação ciliar para a microbacia do rio três cachoeiras, Laguna, SC. Dissertação de Mestrado. Criciúma-SC, Universidade do Extremo Sul Catarinense.

RECORD, S.J.; HESS, R.W.

1943 Timbers of the New World. New Haven: Yale University Press.

SCHEEL-YBERT, R.

1999 Paleoambiente e paleoetnologia de populações sambaquieiras do sudeste do Estado do Rio de Janeiro. Revista do Museu de Arqueologia e Etnologia, 9: 43-59.

2000 Vegetation stability in the southeastern Brazilian coastal area from 5500 to 1400 $14 \mathrm{C}$ yr BP deduced from charcoal analysis. Review of Palaeobotany and Palynology, 110: 111-138.

2001 Vegetation stability in the Brazilian littoral during the late Holocene: anthracological evidence. Revista Pesquisas em Geociências, 28 (2): 315-323.

2004 Teoria e Métodos em Antracologia. 2. Técnicas de campo e laboratório. Arquivos do Museu Nacional, 62 (4): 343-356.

SCHEEL-YBERT, R.; DIAS, O.F.

2007 Corondó: Palaeoenvironmental reconstruction and palaeoethnobotanical considerations in a probable locus of early plant cultivation (south-eastern Brazil). Environmental Archaeology, 12: 129-138. 
SCHEEL-YBERT, R.; EGGERS, S.; WESOLOWSKI, V.; PETRONILHO, C.C.; BOYADJIAN, C.H.; DE BLASIS, P.A.D.; BARBOSA-GUIMARÃES, M.; GASPAR, M.D.

2003 Novas perspectivas na reconstituição do modo de vida dos sambaquieiros: uma abordagem multidisciplinar. Revista de Arqueologia, 16: 109-137.

SCHEEL-YBERT, R.; KLÖKLER, D.; GASPAR, M.D.; FIGUTI, L.

2005 Proposta de amostragem padronizada para macro-vestígios bioarqueológicos: antracologia, arqueobotânica, zooarqueologia. Revista do Museu de Arqueologia e Etnologia, 15-16: 139-163

SCHEEL-YBERT, R.; CARVALHO, M.A.; MOURA, R.P.O.; GONÇALVES, T.A.P.; SCHEEL, M.; YBERT, J.P.

2006 Coleções de referência e bancos de dados de estruturas vegetais: subsídios para estudos paleoecológicos e paleoetnobotânicos. Arquivos do Museu Nacional, 64: 255-266.

SCHERER A.; MARASCHIN-SILVA, F.; BAPTISTA, L.R.M.

2005 Florística e estrutura do componente arbóreo de matas de restinga arenosa no Parque Estadual de Itapuã, RS, Brasil. Acta Botanica Brasilica, 19 (4): 717-726.

SILVA, R.T.

2006 Florística e estrutura da sinúsia arbórea de um fragmento urbano de floresta om- brófila densa do município de Criciúma, Santa Catarina. Dissertação de Mestrado. Criciúma-SC, Universidade do Extremo Sul Catarinense.

SILVA, L.A.; SCARIOT, A.

2004 Comunidade arbórea de uma floresta estacional decídua sobre afloramento calcário na Bacia do Rio Paraná. Revista Árvore, 28 (1): 61-67.

SIMÕES, C.B.

2007 O processo de formação dos sambaquis: uma leitura estratigráfica do sítio Jabuticabeira II, SC. Dissertação de Mestrado. São Paulo, MAE-USP.

SOLARI, M.E.; LEHNEBACH, C.

2004 Pensando la antracología para el centro-sur de Chile: sitios arqueológicos y bosque en el lago Calafquén (IX-X región). Chungará, Revista de Antropología Chilena, Volumen Especial, 4: 373-380.

TILLEY, C.

2004 Can Archaeology Recover Past Intentions? Cambridge Archaeological Journal, 14 (1): 64-67.

2006 Identity, Place, Landscape and Heritage. Journal of Material Culture, 11 (1): 7-32.

VILAGRÁN, X.S.

2008 Análise de arqueofácies na camada de terra preta do sambaqui Jabuticabeira II. Dissertação de Mestrado. São Paulo, MAE-USP. 